\title{
Effects of Aflatoxin on Liver and Protective Effectiveness of Esterified Glucomannan in Merino Rams
}

\author{
Fatma Colakoglu and Hasan Hüseyin Donmez \\ Department of Histology and Embryology, Faculty of Veterinary Medicine, Selçuk University, 42075 Konya, Turkey \\ Correspondence should be addressed to Hasan Hüseyin Donmez, donmez68@hotmail.com
}

Received 9 October 2012; Accepted 28 November 2012

Academic Editors: J. F. Mee and W. Min

Copyright ( $) 2012$ F. Colakoglu and H. H. Donmez. This is an open access article distributed under the Creative Commons Attribution License, which permits unrestricted use, distribution, and reproduction in any medium, provided the original work is properly cited.

\begin{abstract}
The effects of total aflatoxin (AF) given orally on liver in Merino rams were studied. In addition, this study was conducted in order to evaluate the efficacy of an esterified glucomannan (EG) for protection against aflatoxicosis. One-year-old 32 Merino rams were divided into four equal groups. The control group $(\mathrm{C})$ was fed with the commercial feed. The AF group was fed with commercial feed plus $250 \mu \mathrm{g} /$ day of total AF. The EG group was fed with commercial feed plus $2 \mathrm{~g} /$ day of EG. The AF + EG group was fed with commercial feed plus $250 \mu \mathrm{g} /$ day of total AF and $2 \mathrm{~g} /$ day of EG. After feeding period, tissue samples were taken from the liver in order to perform histological analyses. Vacuolar degeneration with small and large droplets and hydropic degeneration in hepatocytes were observed in the AF group. The ceroid pigmentation was observed in macrophages in groups or one by one. It was observed that the fat rate in hepatocytes was $2.6 \%$ in the $\mathrm{C}$ group, $35.5 \%$ in the AF group, $2.9 \%$ in the EG group, and $9.6 \%$ in the $\mathrm{AF}+\mathrm{EG}$ group. In conclusion, the adverse effects caused by aflatoxicosis on the liver could be ameliorated by adding EG to the ration.
\end{abstract}

\section{Introduction}

Mycotoxins are secondary metabolites of microscopic filamentous molds that have adverse effects on humans, animals, and crops that result in illnesses and economic losses [1]. Aflatoxins (AFs) are groups of structurally related mycotoxins produced as food-borne metabolites by toxigenic strains of Aspergillus flavus and A. parasiticus [2]. They are produced on cereal grains during growth, harvest, storage, or transportation [3]. It is well known that AFs are hepatotoxic, hepatocarcinogenic, teratogenic, mutagenic and immunosuppressive [4]. The AFs do not equally affect all animals. The environmental stress, sex, age, and breed differences play a significant role in toxicities. Some are more resistant, such as sheep and cattle, compared with swine, chickens, turkeys, and ducklings which are more susceptible [5]. The liver is the target organ following the ingestion of the toxin. High doses of AFs cause severe hepatocellular necrosis. On the other hand, prolonged low dosage leads to liver enlargements [6].
Prevention of feed and feedstuffs from possible mould growth and AF contamination is very important [7]. Practcial and cost-effective methods for detoxification of $\mathrm{AF}$ containing feed and feedstuff are in great demand [8]. Since the early 1990s, the adsorbent-based several studies have been performed to detoxify AF in contaminated food and foodstuffs and to minimize the deleterious effects of AF [4]. An approach to the problem has been the usage of nonnutritive and inert adsorbents in the diet to bind $\mathrm{AF}$ and reduce the absorption of AF from the gastrointestinal tract [9]. The nonnutritive clays such as aluminosilicates, zeolites, bentonites, and clinoptilolite were preferred by the researchers [4]. In the recent years, researchers suggested that the best approach for decontamination would be biological degradation [10]. Live yeast (Saccharomyces cerevisiae), initially used as a performance promoter in the early 1990s, was found to have beneficial effects on aflatoxicosis [11]. Esterified glucomannan (EG) showed considerably high binding ability (80-97\%) with AF [8], and it has been preferred for detoxification of AF in poultry animals. 
The aim of this study, the effects of total AF given orally on liver in Merino rams, was studied. In addition, this study was conducted in order to evaluate the efficacy of an EG for protection against aflatoxicosis.

\section{Materials and Methods}

2.1. Animals and Diet. Approval for the present study was obtained from the Animal Ethics Committee of the Faculty of Veterinary Medicine of the Selçuk University (2008/061). The study was created from the TUBITAK-TOVAG project entitled "Effects of Aflatoxin on Semen Quality, Testicular Histology, and Hyaluronidase Enzyme Activity, and Protective Effectiveness of Esterified Glucomannan in Ram.”

Thirty-two Merino rams were approximately purchased 1-year old (12-14 months old). Animals were examined for general health. Antiparasitic ivermectin injection (AvromecF, $1 \mathrm{~mL} / 50 \mathrm{~kg}$ ) and oxfendazole (Okzan-F, 1 tablet $/ 50 \mathrm{~kg}$ ) were performed. In addition, enterotoxemia (Pluritoxiven-8, $1 \mathrm{~mL}$ ) and smallpox vaccines were performed. For adaptation to the environment and the new feeding implementation, it was applied the training program 15-days before starting the study. Individually weighted rams were divided into four equal groups. Experimental feeding was continued throughout the ninety-two days. The duration of treatment (92 days) was based on a possible cumulative toxicity and the duration of spermatogenesis and spermiogenesis in rams. The rams were fed a commercial food (Table 1). Water and alfalfa were given ad libitum. AF and EG that were mixed with $250 \mathrm{~g}$ commercial feed were given to animals before morning feeding and then morning feeding was continued.

2.2. Experimental Design. The experimental design consisted of four dietary treatments. The control group (C) was fed with the commercial feed. The AF group was fed with commercial feed plus $250 \mu \mathrm{g} /$ day of total AF. The EG group was fed with commercial feed P 2 g/day of EG. The AF + EG groupwas fed with commercial feed plus $250 \mu \mathrm{g} /$ day of total $\mathrm{AF}$ and $2 \mathrm{~g} /$ day of EG. The AF and EG doses which were given to animals throughout the study were calculated by pharmacologists.

2.3. Aflatoxin. The AF was produced (in the Department of Pharmacology and Toxicology, Faculty of Veterinary Medicine, Selçuk University, Konya, Turkey) from Aspergillus parasiticus NRLL 2999 culture (USDA, Agricultural Research Service, Peoria, IL, USA) via fermentation of rice by the method of Shotwell et al. [12] with minor modifications by Demet et al. [13]. Fermented rice was sterilized in autoclave, dried at $70^{\circ} \mathrm{C}$, and ground to a fine powder. According to the method reported by Vicam [14], extraction and cleaning of AF in fermented rice was used in immunoaffinity column (Down Test; Vicam). The amount of AF measured by high performance liquid chromatography (HPLC) according to the method reported by Stroka et al. [15]. The amount of total $\mathrm{AF}$ in the fermented rice was found $73.96 \mathrm{ppm}$. The $\mathrm{AF}$ within the rice consisted of $84.15 \% \mathrm{AFB}_{1}, 6.29 \% \mathrm{AFB}_{2}$,
TABle 1: Composition of the commercial feed.

\begin{tabular}{lc}
\hline Dry matter & $88 \%$ \\
Crude protein & $12 \%$ \\
Crude cellulous & $12 \%$ \\
Crude ash & $9 \%$ \\
Insoluble ash in HCL & $1.0 \%$ \\
$\mathrm{Ca}$ & $0.6-1.6 \%$ \\
$\mathrm{P}$ & $0.4 \%$ \\
$\mathrm{Na}$ & $0.1-0.4 \%$ \\
$\mathrm{NaCl}$ & $1.0 \%$ \\
$\mathrm{Metabolic}$ energy & $2750 \mathrm{kcal} / \mathrm{kg}$ \\
Vit A & $7000 \mathrm{IU}-\mathrm{kg}$ \\
Vit D3 & $700 \mathrm{IU}-\mathrm{kg}$ \\
Vit E & $25 \mathrm{mg} / \mathrm{kg}$ \\
\hline
\end{tabular}

9.13\% $\mathrm{AFG}_{1}$, and $4.25 \% \mathrm{AFG}_{2}$ (rate of return method 97.4\%; sensitivity $0.4 \mathrm{ppb}$ ).

2.4. Collection and Processing of Tissue Samples. At the end of the 92th day, liver tissue samples were taken from rams after scarification and were fixed in 10\% neutralized buffered formaldehyde, embedded in paraffin wax, and then stained with Crosman's modification of trichrome stain in order to determine the histological structure [16]. In addition, in order to determine fat rate in hepatocytes, liver samples were determined along 16 hours in formol-calcium solution, at $+4^{\circ} \mathrm{C}$, and dark. Sections $(12 \mu \mathrm{m})$ were taken from cryostat, and these were stained with Sudan Black B stain [17]. Fat rate in hepatocytes was determined with the method reported by Gaal et al. [18].

2.5. Statistical Analysis. The obtained results (ratio of fatty liver) were statistically analyzed using Duncan's multiple range test in SPSS software (version 17; SPSS Inc., Chicago, IL, USA). The level of significance was $P<0.05$.

\section{Results}

Histopathologically, no specific lesion was observed in liver tissues from the $\mathrm{C}$ (Figure 1) and EG groups. In the AF group specific lesions were seen in liver. Vacuolar degeneration with small and large droplets (Figure 2) and hydropic degeneration (Figure 2) in hepatocytes, local hyperemia, marked sinusoidal contraction, and a few hepatocytes with pyknotic nuclei in lobules were noticed. Furthermore, the ceroid pigmentation (Figure 2) was observed in macrophages and local hemorrhage areas around central vein. In the AF+EG group was seen a mononuclear cell infiltration in portal areas (Figure 3). Specific lesions like ceroid pigmentation and vacuolar degeneration in this group were not seen. It was found that fat rate in hepatocytes (Table 2) was $2.6 \%$ in the C group, $35.5 \%$ in the AF group, $9.6 \%$ in the AF + EG group and $2.9 \%$ in the EG group. 
TABLE 2: Fat rate in hepatocytes (\%).

\begin{tabular}{lcccc}
\hline Groups $(n=8)$ & $\mathrm{C}$ & AF & EG & AF+EG \\
\hline Fat rate $(\%)$ & $2.63 \pm 0.21^{\mathrm{c}}$ & $35.50 \pm 0.65^{\mathrm{a}}$ & $2.94 \pm 0.25^{\mathrm{c}}$ & $9.63 \pm 0.98^{\mathrm{b}}$ \\
\hline
\end{tabular}

C: control, AF: aflatoxin, EG: glucomannan, AF + EG: aflatoxin + glucomannan.

$\mathrm{a}, \mathrm{b}, \mathrm{c}$ are significantly different $(P<0.05)$.

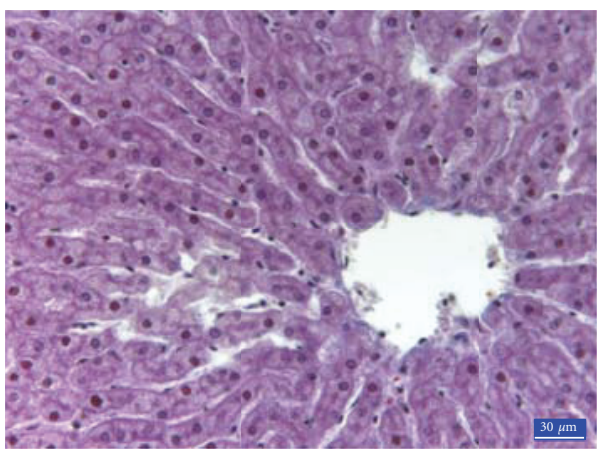

FIGURE 1: Normal histological appearance of the liver in the control group, 3rd region, trichrome staining.

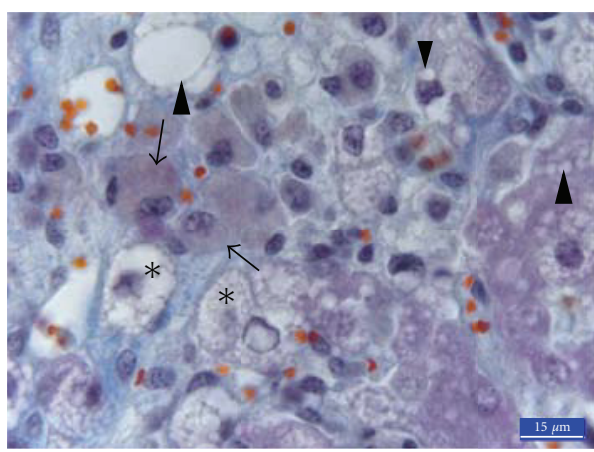

FIGURE 2: Liver histology from an animal contaminated with AF ( $250 \mu \mathrm{g} /$ day of total AF, AF group). Macrophages containing ceroid pigment (arrows), severe vacuolar degeneration in hepatocytes (arrowheads), and hydropic degeneration (stars) in the AF group, 3rd region, trichrome staining.

\section{Discussion}

The liver is considered the main target organ for aflatoxicosis [10]. Lakkawar et al. [6] reported that liver was the most affected organ in rabbits fed an $\mathrm{AFB}_{1}$ contaminated diet. The effects of AFs on histopathological changes are directly correlated with the concentration of $\mathrm{AF}$ and the duration of the exposure [19]. The vacuolar hepatocellular change in animals that were fed $1.6 \mathrm{ppm} \mathrm{AFB}_{1}$ diet continuously throughout 40 weeks was more than animals that were fed diets that contained $0,0.01,0.04,0.4$, or $1.6 \mathrm{ppm} \mathrm{AFB}_{1}$, using an intermittent dosing regimen, 4 weeks on and 4 weeks off $\mathrm{AFB}_{1}$ [20]. In this study, it was observed that $250 \mu \mathrm{g} / \mathrm{day} \mathrm{AF}$ caused significant histopathological changes in liver in 92 days.

Histopathological findings that were caused by AFs in liver were reported as enlarged nuclei, nuclear inclusions, and swollen hepatocytes [19]. Enlarged hepatocytes can arise

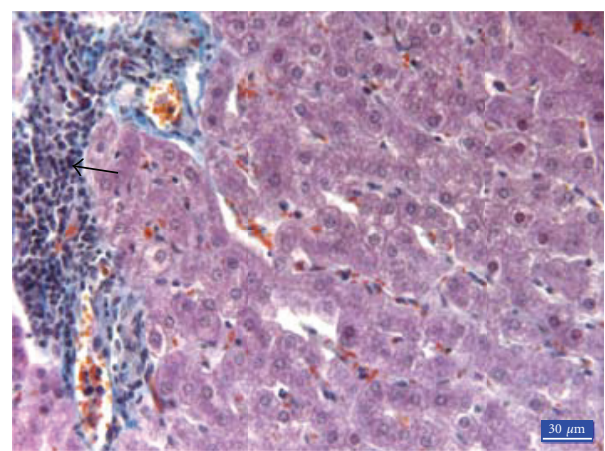

Figure 3: Mononuclear cell infiltration in portal areas in the AF + EG group (arrows), trichrome staining.

from stored metabolism products as a result of shown activities when these cells perform metabolic activities [21], and the AF metabolites arising from the effects of some of the enzymes which react with hepatocyte DNA are thought to be caused by mutations in the nucleus [22]. Yildirım et al. [10] saw that some hepatocytes nuclei were pyknotic and there was nucleus loss in some hepatocytes in the AF group. In this study, we also found a similar finding. A study of Ozen et al. [7] found apparently a dose-dependent mild to severe vacuolar degeneration with irregularly shaped vacuoles in hepatocytes; most of the hepatocytes also contained sharply edged vacuoles that were a sign of fatty accumulation. Kiran et al. [23] reported that hepatic lesions in broilers of the AFtreated group were characterized as diffuse and severe hydropic degeneration and periportal fibrosis. In this study, we also observed vacuolar and hydropic degeneration similar to previous studies $[7,23]$. It was reported that vacuolar degeneration could be due to impaired lipid transport rather than increased lipid biosynthesis [24].

By histological examination of livers in the AF group, Lakkawar et al. [6] observed vascular congestion (up to 30 days), areas of coagulative necrosis around the central veins, and engorged portal areas (from the 40th day onwards) in rabbits. Abdel-Wahhab et al. [25] reported vascular dilation, congestion, and moderate hemorrhages in rats. Hemorrhages in animals of the AF group have also been reported in other studies [26, 27]. Although Salim et al. [28] reported dilated sinusoids depending on the hepatocytes necrosis as a result of aflatoxicosis, we observed sinusoidal contraction depending on the enlargement and swelling of hepatocytes. This finding was in agreement with that reported by Uopasai et al. [29]. Hyperemia was noted where there can be seen sinusoids. Dilation of arterioles causes hyperemia due to increased blood to the tissue depending on inflammation [30]. 
Some researchers have reported cellular disorganization characterized by the accumulation of pigments [19]. In cat's liver which has primary hepatic lipidosis, Gul et al. [31] have seen ceroid pigmentation which is Periodic Acid Schiff (PAS) positive, freely or shaped yellow large droplets in cytoplasm of hepatocyte/Kupffer cells, and more intense in the periportal areas of the liver. In the AF group, we also found hepatocytes and Kupffer's cells which were more intense around the central vein showing ceroid pigmentation. This station is a result of impaired lipid metabolism and severity steatosis [32].

AFs affect primarily the cellular immunity process in most animal species [4]. In the AF-exposed chickens, Yildirım et al. [10] have declared mild mononuclear cell infiltration in the liver's portal areas. In this study, we also observed a similar finding in the AF + EG group. Small inflammatory cell infiltrates composed of lymphocytes, plasma cells, mononuclear cells, and few segmented neutrophils occur to respond to degenerate vacuolated hepatocytes [20].

In this study, histopathological findings obtained from the AF+EG group are close to the $\mathrm{C}$ group. This result has shown that EG is an important adsorbent in decreasing the detrimental effects of AFs. This finding was in agreement with the previous reports $[8,10,19]$.

AF causes impaired lipid transport [24]. The data obtained from this study have also shown that AFs cause fatty liver in rams as in other animals [33]. Furthermore, it has been shown EG decreased significantly that fat rate in hepatocytes and the detrimental effects of AF.

\section{Conclusion}

In conclusion, the adverse effects AF impaired on histological structure of the liver that caus fatty liver could be ameliorated by adding EG to the ration. We conclude EG is an agent which can be used successfully to prevent aflatoxicosis.

\section{Acknowledgments}

The study was supported by TÜBİTAK-TOVAG (Project no. $107 \mathrm{O}$ 866) and the Coordinatorship of Scientific Research Projects of Selcuk University (SU BAP Project no. 09202023).

\section{References}

[1] H. S. Hussein and J. M. Brasel, "Toxicity, metabolism, and impact of mycotoxins on humans and animals," Toxicology, vol. 167, no. 2, pp. 101-134, 2001.

[2] R. J. Verma, "Aflatoxin cause DNA damage," International Journal of Human Genetics, vol. 4, no. 4, pp. 231-236, 2004.

[3] M. H. Salem, K. I. Kamel, M. I. Yousef, G. A. Hassan, and F. D. El-Nouty, "Protective role of ascorbic acid to enhance semen quality of rabbits treated with sublethal doses of aflatoxin B1," Toxicology, vol. 162, no. 3, pp. 209-218, 2001.

[4] H. Oguz, H. H. Hadimli, V. Kurtoglu, and O. Erganis, "Evaluation of humoral immunity of broilers during chronic aflatoxin (50 and $100 \mathrm{ppb}$ ) and clinoptilolite exposure," Revue de Medecine Veterinaire, vol. 154, no. 7, pp. 483-486, 2003.
[5] J. L. Richard, "Discovery of aflatoxins and significant historical features," Toxin Reviews, vol. 27, pp. 171-201, 2008.

[6] A. W. Lakkawar, S. K. Chattopadhyay, and T. S. Johri, "Experimental aflatoxin B1 toxicosis in young rabbits-a clinical and patho-anatomical study," Slovenian Veterinary Research, vol. 41, no. 2, pp. 73-81, 2004.

[7] H. Ozen, M. Karaman, Y. Cigremis et al., "Effectiveness of melatonin on aflatoxicosis in chicks," Research in Veterinary Sciences, vol. 86, pp. 485-489, 2009.

[8] H. Basmacioglu, H. Oguz, M. Ergul, R. Col, and Y. O. Birdane, "Effect of dietary esterified glucomannan on performance, serum biochemistry and haematology in broilers exposed to aflatoxin," Czech Journal of Animal Science, vol. 50, no. 1, pp. 31-39, 2005.

[9] H. Oguz, "A review from experimental trials on detoxification of aflatoxin in poultry feed," Eurasian Journal of Veterinary Sciences, vol. 27, no. 1, pp. 1-12, 2011.

[10] E. Yıldırım, I. Yalcınkaya, M. Kanbur et al., "Effects of yeast glucomannan on performance, some biochemical parameters anf pathological changes in experimental aflatoxicosis in broilers chickens," Revue de Medecine Veterinaire, vol. 162, no. 8-9, pp. 413-420, 2011.

[11] V. G. Stanley, R. Ojo, S. Woldesenbet, D. H. Hutchinson, and L. F. Kubena, "The use of Saccharomyces cerevisiae to suppress the effects of aflatoxicosis in broiler chicks," Poultry Science, vol. 72, no. 10, pp. 1867-1872, 1993.

[12] O. L. Shotwell, C. W. Hasseltine, R. D. Stubblefield et al., "Production of aflatoxin on rice," Applied Microbiology, vol. 5, pp. 425-429, 1966.

[13] O. Demet, H. Oguz, I. Celik et al., "Pirincte aflatoksin uretilmesi," Veteriner Bilimler Dergisi, vol. 11, no. 1, pp. 19-23, 1995.

[14] L. P. Vicam, "Fluorometer USDA-FGIS prodecure for corn, corn meal, corn/soy blend, milled rice, popcorn, sorghum and soybeans," Aflatest Instruction Manuel, pp. 36-38, 1999.

[15] J. Stroka, R. V. Otterdijk, and E. Anklam, "Immunoaffinity column clean-up prior to thin-layer chromatography for the determination of aflatoxins in various food matrices," Journal of Chromatography A, vol. 904, no. 2, pp. 251-256, 2000.

[16] I. Ustunel and R. Demir, Histolojik Boyama Teknikleri, Palme Yayıncilık, Ankara, Turkey, 2001.

[17] K. L. Burdon, "Fatty material in bacteria and fungi revealed by staining dried, fixed slide preparations," Journal of Bacteriology, vol. 52, pp. 665-678, 1946.

[18] T. Gaal, I. M. Reid, and R. A. Collins, "Comparison of biochemical and histological methods of estimating fat content of liver of dairy cows," Research in Veterinary Science, vol. 34, no. 2, pp. 245-248, 1983.

[19] A. S. Baptista, A. L. Abdalla, C. L. Aguiar et al., "Utilization of diets amended with yeast and amino acids for the control of aflatoxicosis," World Journal of Microbiology and Biotechnology, vol. 24, no. 11, pp. 2547-2554, 2008.

[20] D. M. Hinton, M. J. Myers, R. A. Raybourne et al., "Immunotoxicity of aflatoxin B1 in rats: effects on lymphocytes and the inflammatory response in a chronic intermittent dosing study," Toxicological Sciences, vol. 73, no. 2, pp. 362-377, 2003.

[21] O. Nunez, J. D. Hendricks, and G. S. Bailey, "Enhancement of aflatoxin B1 and N-methyl-N'-nitro-N-nitrosoguanidine hepatocarcinogenesis in rainbow trout Salmo gairdneri by 17 $\beta$-estradiol and other organic chemicals," Diseases of Aquatic Organisms, vol. 5, pp. 185-196, 1988.

[22] H. M. Shen, C. N. Ong, and C. Y. Shi, "Involvement of reactive oxygen species in aflatoxin B1-induced cell injury in cultured rat hepatocytes," Toxicology, vol. 99, no. 1-2, pp. 115-123, 1995. 
[23] M. M. Kiran, O. Demet, M. Ortatatlı et al., "The preventive effect of polyvinypolypyrrolidone on aflatoxicosis in broilers," Avian Pathology, vol. 27, no. 3, pp. 250-255, 1998.

[24] M. McLean and M. F. Dutton, "Cellular interactions and metabolism of aflatoxin: an update," Pharmacology and Therapeutics, vol. 65, no. 2, pp. 163-192, 1995.

[25] M. A. Abdel-Wahhab, S. A. Nada, and F. A. Khalil, "Physiological and toxicological responses in rats fed aflatoxincontaminated diet with or without sorbent materials," Animal Feed Science and Technology, vol. 97, no. 3-4, pp. 209-219, 2002.

[26] D. C. Baker and R. A. Green, "Coagulation defects of aflatoxins in toxicated rabbits," Veterinary Pathology, vol. 24, pp. 62-70, 1987.

[27] R. Dafalla, A. Yagi, and S. Adam, "Experimental aflatoxicosis in hybro-type chicks: sequential changes in growth and serum constituents and histopathological changes," Veterinary and Human Toxicology, vol. 29, pp. 222-225, 1987.

[28] A. B. Salim, A. Zohair, A. E. S. Hegazy et al., "Effect of some strains of probiotic bacteria against toxicity induced by aflatoxins in vivo," The Journal of American Science, vol. 7, no. 1, pp. 1-12, 2011.

[29] S. Uopasai, K. Pimpukdee, B. Tengjaroenkul et al., "Effect of natural charcoal powder added in swine feeds as aflatoxin adsorbents on improving performance of swine production and histopathological changes of swine livers," KKU Veterinary Journal, vol. 18, no. 2, pp. 109-119, 2008.

[30] T. Unal, Hemodinamik Bozukluklar, Ege Üniversitesi Diş Hekimliği Fakültesi, 2012.

[31] Y. Gul, O. Kızıl, and A. O. Ceribası, "Bir kedide primer hepatik lipidozis olgusu," Fırat Üniversitesi Sağlık Bilimleri Veteriner Dergisi, vol. 20, no. 5, pp. 375-378, 2006.

[32] U. H. Milli and R. Hazıroglu, Veteriner Patoloji, Medisan, Ankara, Turkey, 2000.

[33] Z. Yener, I. Celik, F. Ilhan, and R. Bal, "Effects of Urtica dioica L. seed on lipid peroxidation, antioxidants and liver pathology in aflatoxin-induced tissue injury in rats," Food and Chemical Toxicology, vol. 47, no. 2, pp. 418-424, 2009. 

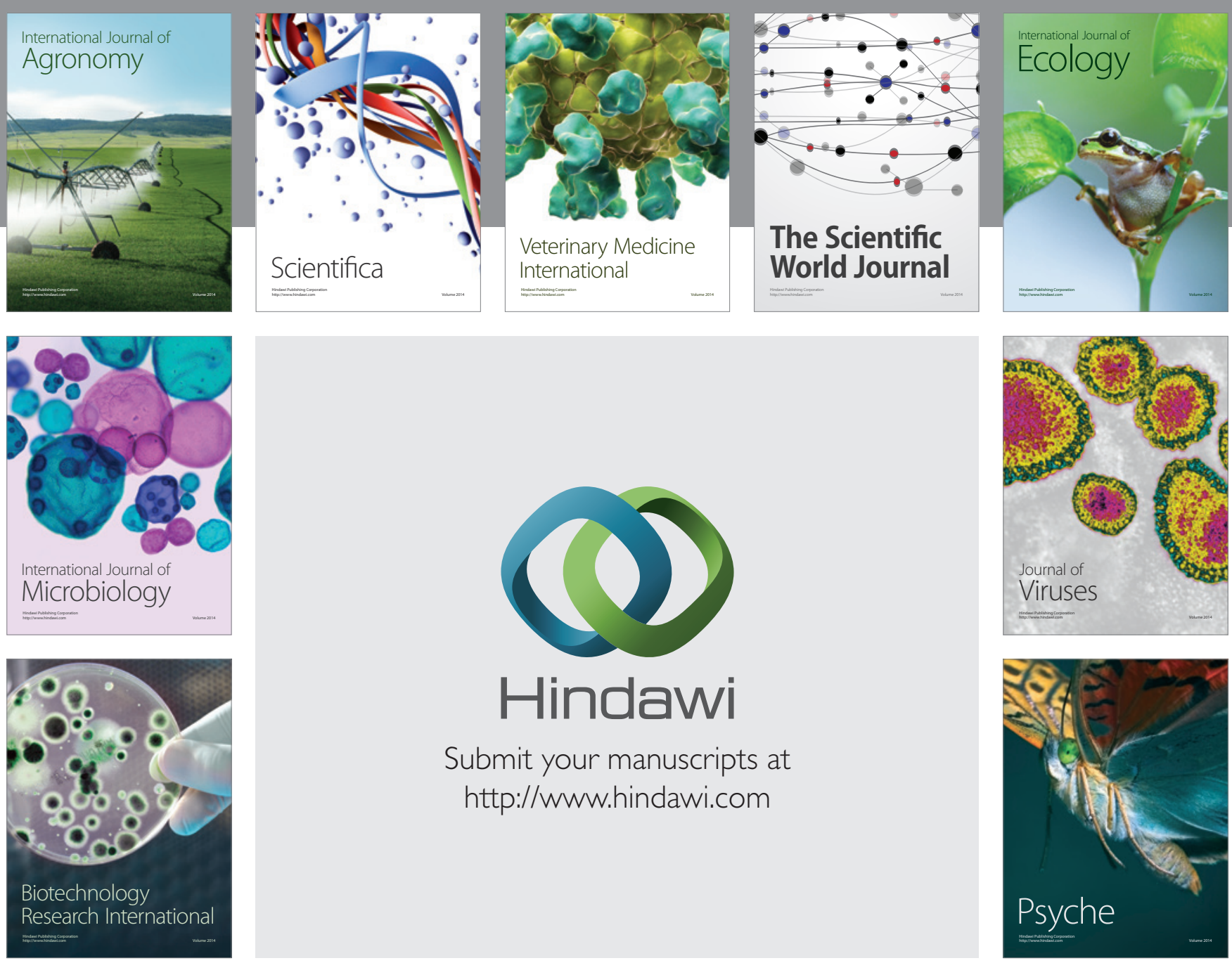

Submit your manuscripts at

http://www.hindawi.com
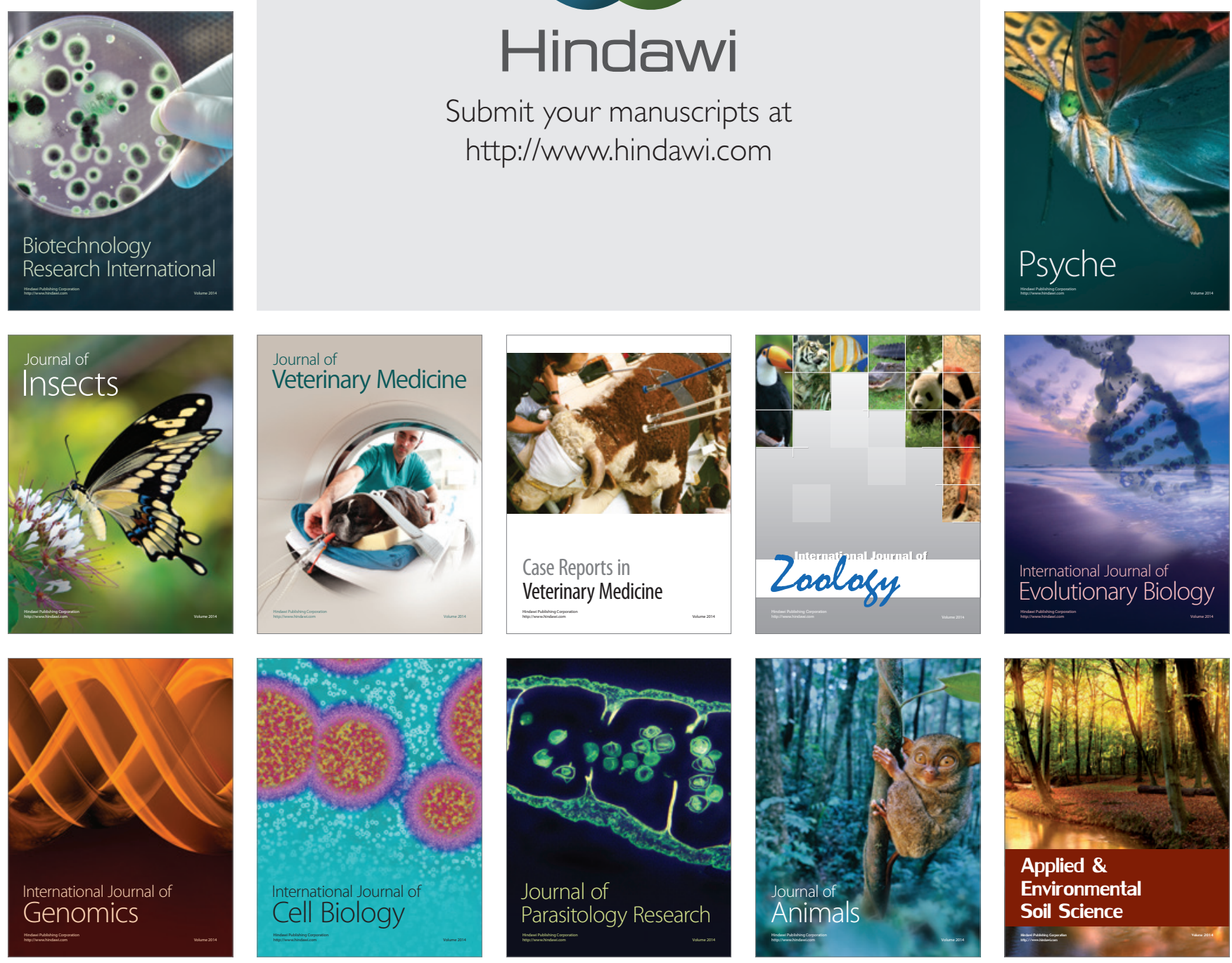